\title{
serie Anti-piracy policy and quality differential in markets for information
}


Los documentos de trabajo del Ivie ofrecen un avance de los resultados de las investigaciones económicas en curso, con objeto de generar un proceso de discusión previo a su remisión a las revistas científicas. Al publicar este documento de trabajo, el Ivie no asume responsabilidad sobre su contenido.

Ivie working papers offer in advance the results of economic research under way in order to encourage a discussion process before sending them to scientific journals for their final publication. Ivie's decision to publish this working paper does not imply any responsibility for its content.

La Serie AD es continuadora de la labor iniciada por el Departamento de Fundamentos de Análisis Económico de la Universidad de Alicante en su colección "A DISCUSIÓN" y difunde trabajos de marcado contenido teórico. Esta serie es coordinada por Carmen Herrero.

The AD series, coordinated by Carmen Herrero, is a continuation of the work initiated by the Department of Economic Analysis of the Universidad de Alicante in its collection "A DISCUSIÓN", providing and distributing papers marked by their theoretical content.

Todos los documentos de trabajo están disponibles de forma gratuita en la web del Ivie http:/ / www.ivie.es, así como las instrucciones para los autores que desean publicar en nuestras series.

Working papers can be downloaded free of charge from the Ivie website http://www.ivie.es, as well as the instructions for authors who are interested in publishing in our series.

Edita / Published by: Instituto Valenciano de Investigaciones Económicas, S.A.

Depósito Legal / Legal Deposit no.: V-252-011

Impreso en España (enero 2011) / Printed in Spain (January 2011) 
WP-AD 2011-02

\title{
Anti-piracy policy and quality differential in markets for information goods
}

\author{
Javier M. López-Cuñat and \\ Francisco Martínez-Sánchez
}

\begin{abstract}
In this paper we analyze the strategic decisions of the government, the incumbent and the pirate in a market where the good is piratable. We show that deterred or accommodated piracy can occur in equilibrium, but pure monopoly cannot occur for any anti-piracy policy. We also show that the initial quality differential between the original and the pirated product is essential to explain the effects of an increase in the quality of pirated product on both the level of piracy and the optimal monitoring rate. Assuming a onestage entry process and a sufficiently high quality differential, we prove that the incumbent always prefers to move first and make a credible commitment to a price. However, this is not true with a two-stage entry process.
\end{abstract}

Keywords: for-profit piracy, quality, monitoring, price competition.

JEL Classification: K42, L13, L86.

\footnotetext{
"We acknowledge financial support from the Spanish Ministerio de Ciencia e Innovación and FEDER funds under projects SEJ-2007-62656 and ECO2010-19830, Junta de Andalucía under project P08-SEJ-03781 and the Instituto Valenciano de Investigaciones Económicas.

J.M. López-Cuñat: University of Alicante. Contact author: cunyat@ua.es. F. MartínezSánchez: University of Murcia.
} 


\section{Introduction}

Most of theoretical efforts devoted to analyze the causes and consequences of copying and piracy have been focused on end-user copying, which refers to non-commercial copying by final consumers. In many countries this activity is considered legal since most of consumers do not copy with the intention of making a profit. Thus, end-user copying is not prosecuted in many countries and governments' anti-piracy policies concentrate mainly on for-profit piracy, which takes place when firms (the pirates) illegally reproduce and sell copies of an original product. Peitz and Waelbroeck (2006) provide a good survey of the literature and confirm that there are few studies on for-profit piracy.

Several evidences indicate that both activities, for-profit piracy and enduser copying, have a great economic significance. For instance, the Fourth Annual BSA and IDC Global Software Piracy Study reveals that 35\% of the software installed in 2006 on personal computers worldwide was obtained illegally, amounting to nearly $\$ 40$ billion in global losses. ${ }^{1}$ Although this study does not distinguish between commercial piracy and end-user copying, it suggests the importance of analyzing the latter form of piracy. Commercial piracy is very significant in music industry. The International Federation of the Phonographic Industry (IFPI) reports that $37 \%$ of all CDs purchased in 2005 were pirate, and the global traffic of pirate product was worth $\$ 4.5$ billion based on pirate prices. $^{2}$

The growing theoretical economic literature on commercial piracy focus on the consequences of piracy on profits and welfare. Some of considered topics are the role of government's anti-piracy policies, the protection against piracy by the vendor of the original product (incumbent firm) in opposition to the effect of network externalities generated by the pirate, the consequences of price competition against the pirate, and the effects of lobbying by the incumbent firm. Our study focus mainly on the former theme. The aim of the present paper is to provide a positive analysis of the strategic interaction between a firm who introduces a new product on the market, a pirate who can enter and produce a lower-quality copy of it, and the government who sets the intellectual property rights protection (IPRP). As most of published theoretical studies, we assume a simple form of IPRP consisting of monitoring and penalties for piracy. We are particularly interested in studying how price competition and government policy influence the final outcome. So, we make the model simple without considering networks effects, advertising and quality choices. Nevertheless, we also perform some comparative statics to better understand the effects of quality differential, between the original and the pirated product, on both the optimal monitoring rate and the amount of piracy.

Before discussing our model, we must emphasize that there is empirical evidence supporting that prices can constitute a strategy against piracy. Papadopoulos (2003) examines the relative strength and significance of some institutional and economic variables that influence the country specific levels of sound recording piracy. He finds a positive and significant relationship between the price-earnings ratio and the sound recording piracy market share.

In this paper, we analyze a model in which, after the anti-piracy policy is

\footnotetext{
${ }^{1}$ http://w3.bsa.org/globalstudy//

2 The Recording Industry 2006 Piracy Report available at //www.ifpi.org/content/section_statistics/index.htm
} 
made public by the government, the incumbent chooses the price of the original product and then, taking into account such price, the pirate decides whether to enter or not with a lower-quality version of the original product. ${ }^{3}$ Finally, each consumer buys at most one of the two products according to her valuation of quality and profits are realized. The government maximizes social welfare and the anti-piracy policy is implemented at the end of the game.

We have find several remarkable differences with previous studies and new insights. First, our analysis implies that, as a consequence of the government's policy, the incumbent can deter the pirate from entry in equilibrium. ${ }^{4}$ Second, we show that pure monopoly cannot occur in equilibrium for any anti-piracy policy. Third, our study provides new understandings relative to the effects of qualities on equilibrium. Some comparative statics lead us to show that the initial quality differential between the original and the pirated product is critical. On the one hand, the standard result that an increase in the quality of pirated product enlarges piracy should be revised. We show that this is a local conclusion because, when the initial quality differential is low enough, an increase in the quality of pirated product may deter piracy if we consider the whole subgame perfect equilibrium. On the other hand, we prove that the effects of qualities on the optimal monitoring rate which deters entry depend on the initial quality differential. If it is low enough, an increase in the quality of the pirated product may decrease the optimal monitoring rate. Nevertheless, if the initial quality differential is high enough, a local increase in the quality of the pirated product may increase the optimal monitoring rate, but a no local increase may decrease it.

The last contribution of this paper is to provide an answer for the case in which the incumbent strategically chooses whether or not to commit to a price. To that purpose, we analyze an extended game where the incumbent decides between to make or not to make a credible commitment to a price. In the first case, the game continues as in the previous model. In the second case, the incumbent and the pirate make simultaneous decisions. Our analysis shows that some previous results in the literature should be carefully reconsidered. If, as in the current literature, we assume a two-stage entry process, ${ }^{5}$ we show that there are anti-piracy policies for which the incumbent prefers not to make a credible commitment to a price and to move simultaneously with the pirate. However, when we assume a one-stage entry process (i.e. when the pirate cannot commit to entry before pricing) and a sufficiently high quality differential, we show that the incumbent prefers to move first and make a credible commitment to a price.

\footnotetext{
${ }^{3}$ Therefore, the incumbent commits to the price of the original product. We will discuss later the relaxation of such hypothesis.

${ }^{4}$ Piracy deterrence has been analyzed in models with end-users copying, as in Bae and Choi (2006) and Chang et al. (2008).

${ }^{5}$ The pirate decides first on entry an then, in the case of entry, the pirate and the incumbent make simultaneous decisions on prices.
} 
The paper is organized as follows. In Section 2, we comment on the existing literature and relate our work to previous analyses. Section 3 sets up our model. In Section 4 we compute the subgame perfect equilibrium (SPE) that corresponds to each anti-piracy policy. The socially optimal policy and the possible equilibria are obtained in Section 5. Section 6 is devoted to analyze the effects of qualities on the equilibrium. In Section 7 , we extend the previous model by allowing the incumbent to choose whether or not to commit to a price. Finally, Section 8 contains the conclusions.

\section{Related literature}

Our model is constructed from Banerjee (2003), who analyzes the government's role in controlling piracy by means of a vertical differentiation model in which the incumbent sells original software and the pirate illegally reproduces and sells copies of it. Although we incorporate minor improvements into the framework, there is an important difference relative to the assumed behavior of the pirate. Banerjee (2003) supposes that the pirate does not decide strategically on entry and, therefore, he analyzes two cases: the leader-follower game and the monopoly pricing game. ${ }^{6}$ Therefore, piracy cannot constitute a full device to discipline the incumbent's behavior and this explains the differences with our results. First, as a consequence of the hypothesis, Banerjee (2003) finds that the incumbent does not deter the pirate from entry in equilibrium. This contrasts with our findings. Second, unlike our analysis, Banerjee (2003) shows that pure monopoly can be attained for some anti-piracy policies. Third, assuming a twostage decision-making, he proves that the incumbent prefers to move first and choose a price (i.e. acting as a leader) to choose his price simultaneously with the pirate for any anti-piracy policy. In our model, in which the pirate is a stronger competitor, this is not true. Finally, relative to the effects of qualities, Banerjee (2003) shows that an increase in the quality of the pirated product increases piracy, and also increases the optimal monitoring rate for which the government induces the monopoly outcome. Our analysis proves that these results can be reversed when we consider the initial quality differential and the whole subgame perfect equilibrium.

Banerjee (2006) analyzes lobbying by the incumbent who tries to prevent commercial piracy. He assumes that the pirate does not decide strategically on entry and besides consumers decide their purchase strategies before knowing the availability of the pirated software. ${ }^{7}$ This consumers' capacity for commitment could constitute a device to discipline the incumbent's behavior that would be a rationale for the results. He shows that not monitoring is the socially optimal policy. Nevertheless, special interest lobbying by the incumbent may result in monitoring as the socially optimal outcome.

\footnotetext{
${ }^{6}$ In the leader-follower game, the incumbent's prices and profits are identical in equilibrium, with and without piracy [see Banerjee (2003, page 103)]. Moreover, throughout Banerjee's (2003) analysis there is no maximization of the incumbent's profits subject to non-negative pirate's profits.

${ }^{7}$ The consumer's expected utility is computed under each strategy taking into account the probability that the pirated software is available [see Banerjee (2006, page 143)].
} 
Poddar (2005a) analyzes commercial piracy when network externalities are present, assuming that the network effects generated by the pirated software are weaker than the ones caused by the original software. The pirated software is a lower-quality version of the original one, and entry decisions are not considered. Prices are chosen simultaneously and consumers have different valuations for the software. He proves that, unlike earlier findings on end-user piracy, the incumbent prefers to protect its product (as opposed to allowing piracy) for any degree of the importance of network size.

In Poddar (2005b), the incumbent can incur a R\&D cost to deter the entry of the pirate. The incumbent's R\&D invest raises the pirate's cost of production of the pirated software. The original software is more reliable than the pirated one. The competition stage is modeled assuming that prices are chosen simultaneously and that consumers have different valuations for the software. Both, for end-user and commercial piracy, Poddar (2005b) finds that there is piracy when software users are heterogeneous enough, when the effectiveness of incumbent's R\&D is low enough, and when the pirated software is moderately reliable.

Kiema (2008) considers a model where the incumbent acts as a leader in prices who competes against several commercial pirates, who enter the market until it becomes unprofitable. Each pirate chooses the price and the amount of advertising, and incurs an advertising cost (like a variable cost of production) and a fixed cost (the costs caused by DRM systems). The analysis implies two main conclusions. On the one hand, an increase in the fixed cost increases the incumbent's profit. On the other hand, an increase in the advertising cost might increase the profits of the commercial pirates and decrease the incumbent's profits.

Finally, considering a sequential duopoly model with vertical differentiation and price competition, Martínez-Sánchez (2010) analyzes the reasons why a pirate could act as a leader in prices, taking into account the government and incumbent's decisions to prevent piracy. He shows that the government will not help the incumbent to become a monopolist, even if he installs an antipiracy system. However, depending on the technology for monitoring piracy, the government will induce that the pirate enters as a follower or as a leader, or encourage the incumbent to deter the entry of the pirate. The pirate decides to become a leader to avoid being brought down by the incumbent and the government.

\section{The model}

We consider a model with basic features taken from the standard studies of price-quality competition [see, for instance, Tirole (1988, Section 7.5) and the references contained therein]. There are four types of agents: consumers, the developer of a new product (incumbent), a pirate who illegally reproduces and sells it, and the government, which is responsible for monitoring and penalizing the pirate. 
There is a continuum of consumers indexed by $\theta$, with $\theta \in[0, \bar{\theta}]$. The index $\theta$ is assumed to follow a uniform distribution, and represents the consumers' tastes for the quality of the product. We assume that there is no resale market for used product. Each consumer is assumed to buy at most a unit of the product.

The utility of a type $\theta$ consumer is,

$$
U(\theta)=\left\{\begin{array}{cl}
\theta q_{i}-p_{i} & \text { if the consumer buys the original product } \\
\theta q_{p}-p_{p} & \text { if the consumer buys the pirated product } \\
0 & \text { if the consumer does not buy }
\end{array}\right.
$$

where $p_{i}, q_{i}, p_{p}$ and $q_{p}$ are the price and quality of the original and the pirated product, respectively. We assume $q_{i}>q_{p}>0$. Let $r=q_{i} / q_{p}>1$ be the ratio of qualities.

Since qualities are common knowledge, decisions on prices are equivalent to decisions on quality-deflated prices. So, we consider that the incumbent and the pirate decide on hedonic prices $x_{i}=p_{i} / q_{i}$ and $x_{p}=p_{p} / q_{p}$ respectively. Without loss of generality, we also assume that $x_{i}, x_{p} \in[0, \bar{\theta}] .{ }^{8}$

Demand functions are obtained from the indifferent consumers according to expression (1). When the pirate is not in the market, consumers only observe $x_{i}$ and the incumbent faces the monopoly demand:

$$
D_{i}\left(x_{i}\right)=\bar{\theta}-x_{i}
$$

where $\theta_{i}=x_{i}$ is the consumer who is indifferent between buying the original product and not buying. Of course, the pirate's demand is $D_{p} \equiv 0$ in this case, which is trivial. Thus, the analysis focus on the duopolistic setting.

If the pirate is in the market, consumers consider both offers, the legal and the illegal one, and three kinds of indifferent consumers may exist. First, if there is a consumer who is indifferent between buying the original and the pirated product, he must be $\theta_{o}=\left(p_{i}-p_{p}\right) /\left(q_{i}-q_{p}\right)$, or, equivalently, $\theta_{o}=$ $\left(r x_{i}-x_{p}\right) /(r-1)$. Second, if there is a consumer who is indifferent between buying from the pirate and not buying at all, he must be $\theta_{p}=x_{p}$. Third, there may be a consumer who is indifferent between buying the original product and not buying at all, when the pirate fixes a very high price. This consumer must be $\theta_{i}=x_{i}$. Some easy calculations show that the demands faced by the incumbent and the pirate are

\footnotetext{
${ }^{8}$ Our technical specification is similar to Ronnen's (1991) approach, in which hedonic prices are considered instead of usual prices. Of course, our analysis can be equivalently carried out without hedonic prices. The best response prices that we obtain are obviously similar to those in Ronnen (1991).
} 


$$
D_{i}\left(x_{i}, x_{p}\right)= \begin{cases}\bar{\theta}-x_{i} & \text { if } x_{i} \leq x_{p} \\ \bar{\theta}-\min \left\{\bar{\theta}, \frac{r x_{i}-x_{p}}{r-1}\right\} & \text { if } x_{i} \geq x_{p}\end{cases}
$$

and

$$
D_{p}\left(x_{i}, x_{p}\right)= \begin{cases}0 & \text { if } x_{i} \leq x_{p} \\ \min \left\{\bar{\theta}, \frac{r x_{i}-x_{p}}{r-1}\right\}-x_{p} & \text { if } x_{i} \geq x_{p} .\end{cases}
$$

We assume that consumers do not face the risk of prosecution from the use of copies. The government is responsible for monitoring and penalizing the pirate. Let $\alpha$ and $G$ be the monitoring rate and the penalty respectively. So, $\alpha$ is the probability of detecting the pirate. Let $C(\alpha)$ be the cost of monitoring. We assume $C(0)=0, C^{\prime}(\alpha)>0, C^{\prime}(0)=0, C^{\prime \prime}(\alpha)>0$. The government chooses $\alpha$ and $G$ to maximize the social welfare. We assume $0 \leq G \leq \bar{G}$, where $\bar{G}$ is the limit of the penalty.

We assume that if the pirate's illegal operations are detected, which occurs with probability $\alpha$, he must pay the penalty $G$ and loses his income. The expected profits of the incumbent and the pirate, taken into account that the detection is made after the sales, are:

$$
\pi_{i}(\cdot)=p_{i} D_{i}(\cdot)
$$

and

$$
\pi_{p}(\cdot)=(1-\alpha) p_{p} D_{p}(\cdot)-\alpha G .
$$

We assume that qualities are parameters of the model. ${ }^{9}$ The cost incurred by the incumbent to develop the new product is a sunk cost, and the production cost is assumed to be zero. We also assume that the pirate can duplicate without costs the new product. Therefore, we assume zero marginal costs of both an original production and a pirated one. This is a plausible assumption for information goods. Typically, these goods entail high fixed costs but low (often zero) marginal costs [see, for instance, Varian (2001a), Varian (2001b), Belleflamme (2005)]. Moreover, in our model, demand and profits functions are continuous and piecewise differentiable. Equilibrium prices are positive because we assume $r>1$. Therefore, for each $r>1$, our conclusions hold for positive marginal costs if they are low enough.

The government's net expected revenue is

$$
R= \begin{cases}\alpha G+\alpha \delta I_{p}(\cdot)-C(\alpha), & \text { if the pirate is in the market; } \\ -C(\alpha), & \text { otherwise. }\end{cases}
$$

where $I_{p}(\cdot)$ represents the pirate's revenue and $\delta \in[0,1]$ represents the government's capacity to reuse the revenue seized to the pirate. In the absence of monitoring, the penalty is irrelevant. So we assume $G=0$ if $\alpha=0$.

The social welfare is the sum of the profits of the incumbent and the pirate, the consumer surplus and the net expected revenue of the government.

The complete information game, which is analyzed in Sections $4-5$, is the following. ${ }^{10}$

\footnotetext{
${ }^{9}$ Quality choice models with vertical differentiation are Motta (1993), Crampes and Hollander (1995), and Wauthy (1996).

${ }^{10} \mathrm{An}$ analysis of for-profit piracy in which the pirate can either price first or wait until the incumbent prices is Martínez-Sánchez (2010).
} 
Stage 1. The government announces $\alpha$ and $G$ to maximize social welfare, and the incumbent and the pirate observe the policy variables.

Stage 2. The incumbent moves first and chooses a price for the new product. The pirate observes such price, chooses a price for the pirated product and decides whether to enter or not.

Stage 3. Consumers observe the price of the original product and possibly the price of the pirated product, and buy at most one product. Finally, monitoring takes place.

\section{Market equilibrium}

In this section, we obtain the subgame perfect equilibrium corresponding to the two last stages by backward induction. First, we compute the best price for the pirate, given the incumbent's price, and we deduce the pirate's optimal decision on entry. Second, we determine the incumbent's optimal price by maximizing the profit induced by the pirate's best response.

The pirate's optimal hedonic price, given the incumbent's choice, is obtained by maximizing the pirate's profit in (6). The proof is available upon request from the authors. It is similar to the one computed by Ronnen (1991):

$$
x_{p}^{B R}\left(x_{i}\right)= \begin{cases}x_{i} / 2 & \text { if } 0 \leq x_{i} \leq \frac{2(r-1) \bar{\theta}}{2 r-1} \\ r x_{i}-(r-1) \bar{\theta} & \text { if } \frac{2(r-1) \bar{\theta}}{2 r-1} \leq x_{i} \leq \frac{(2 r-1) \bar{\theta}}{2 r} \\ \bar{\theta} / 2 & \text { if } \frac{(2 r-1) \bar{\theta}}{2 r} \leq x_{i} \leq \bar{\theta} .\end{cases}
$$

By substituting (7) into the pirate's profit, we obtain the continuation pirate's profit in a SPE when he enters and chooses his optimal hedonic price:

$\pi_{p}^{c}\left(x_{i}\right)= \begin{cases}(1-\alpha) q_{i} \frac{x_{i}^{2}}{4(r-1)}-\alpha G & \text { if } 0 \leq x_{i} \leq \frac{2(r-1) \bar{\theta}}{2 r-1}, \\ (1-\alpha) q_{i}\left[r x_{i}-(r-1) \bar{\theta}\right]\left(\bar{\theta}-x_{i}\right)-\alpha G & \text { if } \frac{2(r-1) \bar{\theta}}{2 r-1} \leq x_{i} \leq \frac{(2 r-1) \bar{\theta}}{2 r}, \\ (1-\alpha) q_{i} \frac{\bar{\theta}^{2}}{4 r}-\alpha G & \text { if } \frac{(2 r-1) \bar{\theta}}{2 r} \leq x_{i} \leq \bar{\theta} .\end{cases}$

The pirate decides to enter in the market when $\pi_{p}^{c}\left(x_{i}\right)>0$. A more convenient way to express this is by the inequality $x_{i}>x_{i}^{d}(g)$, where

$$
x_{i}^{d}(g)= \begin{cases}2 \sqrt{(r-1) g} & \text { if } 0 \leq g \leq \frac{(r-1) \bar{\theta}^{2}}{(2 r-1)^{2}} \\ \frac{(2 r-1) \bar{\theta}-\sqrt{\bar{\theta}^{2}-4 r g}}{2 r} & \text { if } \frac{(r-1) \bar{\theta}^{2}}{(2 r-1)^{2}} \leq g \leq \frac{\bar{\theta}^{2}}{4 r} \\ +\infty & \text { if } \frac{\bar{\theta}^{2}}{4 r}<g\end{cases}
$$

and $g=\frac{\alpha G}{q_{i}(1-\alpha)}$. We can interpret the compound variable $g$ as a measure of the government's effort to avoid piracy, since it increases with $\alpha$ and $G$. The price $x_{i}^{d}(g)$ is the incumbent's hedonic price that deters piracy, given the antipiracy effort level. Therefore, the pirate's optimal decisions will be: to enter and choose the price $x_{p}^{B R}\left(x_{i}\right)$ if $x_{i}>x_{i}^{d}(g)$, and not to enter if $x_{i} \leq x_{i}^{d}(g)$. The graph of $x_{i}^{d}(\cdot)$ is represented in figure 1 . Since $x_{i}^{d}(\cdot)$ is increasing in $g$, piracy is less likely when the anti-piracy effort is hard if $r$ is constant. For a fixed $g$, since the graph of $x_{i}^{d}(\cdot)$ moves upwards if $r$ increases, piracy also is less likely when the quality of the pirated product is low. 


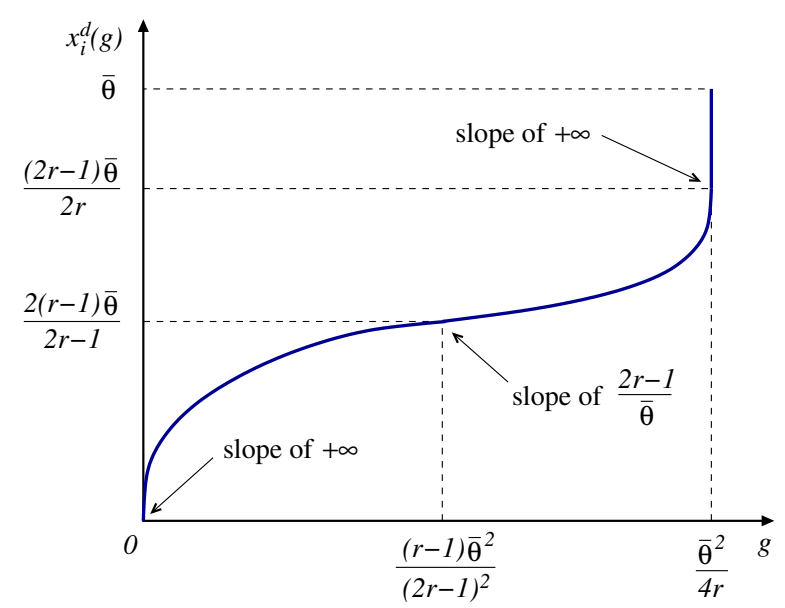

Figure 1: The limit price to deterring piracy.

According to the previous pirate's optimal decision, the incumbent's continuation profit as a function of his price $x_{i}$ is:

$$
\pi_{i}^{c}\left(x_{i}\right)= \begin{cases}q_{i} x_{i}\left(\bar{\theta}-x_{i}\right) & \text { if } 0 \leq x_{i} \leq x_{i}^{d}(g), \\ q_{i} x_{i} D_{i}\left(x_{i}, x_{p}^{B R}\left(x_{i}\right)\right) & \text { if } x_{i}^{d}(g)<x_{i} \leq \bar{\theta} .\end{cases}
$$

This shows that, in any SPE, the incumbent and pirate's optimal strategies depend intuitively on the government's anti-piracy policy. If the policy is very mild ( $g$ very low), the pirate will always enter the market and the incumbent will choose a price by taking into account the pirate's optimal reaction. We can interpret this case saying that the government induces "accommodated piracy" following a terminology similar to Bain's (1956) taxonomy. Easy computations show that the incumbent's hedonic price in this regime is: ${ }^{11}$

$$
x_{i}^{f}=\frac{(r-1) \bar{\theta}}{2 r-1} .
$$

If the policy is very strong ( $g$ very high), the pirate will never enter, and the incumbent will act as a pure monopolist. In this case, the government induces "blockaded piracy", and the incumbent's price will be: ${ }^{12}$

$$
x_{i}^{m}=\frac{\bar{\theta}}{2} .
$$

However, for an intermediate range of anti-piracy effort levels, the incumbent will find optimal to avoid piracy by choosing the price $x_{i}^{d}(g)$. In this case, government induces "deterred piracy". ${ }^{13}$ The next proposition summarizes the optimal strategies. A sketch of proof is provided in the appendix and the full proof is available upon request.

\footnotetext{
${ }^{11}$ As a superscript, $f$ indicates that the pirate is the follower in this case.

${ }^{12}$ This regime of full monopoly is indicated with $m$ as a superscript.

${ }^{13}$ As a superscript, $d$ will indicate this regime.
} 
Proposition 1 In any SPE, the incumbent and pirate's optimal strategies are the following:

(a) The pirate will enter the market only if $x_{i}>x_{i}^{d}(g)$, where $x_{i}^{d}(g)$ is defined in (8), and choose the price according to (7).

(b) The incumbent will choose the price $x_{i}^{*}=x_{i}^{f}>x_{i}^{d}(g)$ if $g<g^{d}$, where

$$
g^{d}=\frac{\bar{\theta}^{2}(r-\sqrt{2 r-1})}{8(r-1)(2 r-1)} .
$$

(c) The incumbent will choose the price $x_{i}^{*}=x_{i}^{d}(g)$ if $g^{d} \leq g \leq g^{m}$, where

$$
g^{m}= \begin{cases}\frac{\bar{\theta}^{2}(2-r)}{4} & \text { if } 1<r \leq 3 / 2, \\ \frac{\bar{\theta}^{2}}{16(r-1)} & \text { if } r \geq 3 / 2 .\end{cases}
$$

(d) The incumbent will choose the price $x_{i}^{*}=x_{i}^{m}$ if $g^{m} \leq g$.

\section{The optimal policy}

In this section we will obtain the government's optimal policy according to the SPE of the game. Backwards induction leads us to consider the social welfare for each one of the three possible regimes.

Consumer surplus is

$$
C S=\int_{\theta_{p}}^{\theta_{o}}\left(\theta q_{p}-p_{p}\right) d \theta+\int_{\theta_{o}}^{\bar{\theta}}\left(\theta q_{i}-p_{i}\right) d \theta .
$$

From the previous optimal strategies, easy calculations imply the following values of the consumer surplus, the incumbent's profit and the pirate's revenue, where $f, d$ and $m$ indicate, as superscripts, the three previous regimes under which the values are calculated.

$$
\begin{array}{ll}
C S^{f}=\frac{q_{i} \bar{\theta}^{2}\left(4 r^{2}+r-1\right)}{8(2 r-1)^{2}}, & \pi_{i}^{f}=\frac{q_{i} \bar{\theta}^{2}(r-1)}{2(2 r-1)}, \quad I_{p}^{f}=\frac{q_{i} \bar{\theta}^{2}(r-1)}{4(2 r-1)^{2}}, \\
C S^{d}(g)=\frac{q_{i}\left(\bar{\theta}-x_{i}^{d}(g)\right)^{2}}{2}, & \pi_{i}^{d}(g)=q_{i} x_{i}^{d}(g)\left[\bar{\theta}-x_{i}^{d}(g)\right], \\
C S^{m}=\frac{q_{i} \bar{\theta}^{2}}{8}, & \pi_{i}^{m}=\frac{q_{i} \bar{\theta}^{2}}{4} .
\end{array}
$$

Proposition 1 implies that, in any SPE, the government anticipates the following social welfare function at stage 1 :

$$
W(\alpha, G)= \begin{cases}C S^{f}+\pi_{i}^{f}+(1-\alpha+\alpha \delta) I_{p}^{f}-C(\alpha) & \text { if } 0 \leq g<g^{d}, \\ C S^{d}(g)+\pi_{i}^{d}(g)-C(\alpha) & \text { if } g^{d} \leq g \leq g^{m}, \\ C S^{m}+\pi_{i}^{m}-C(\alpha) & \text { if } g^{m} \leq g,\end{cases}
$$

It depends on $(\alpha, G)$ and the parameters of the model taking into account the compound variable $g=\frac{\alpha G}{q_{i}(1-\alpha)}$.

The government will maximize $(16)$ on $(\alpha, G) \in[0,1] \times[0, \bar{G}]$. Since monitoring is costly, the lowest monitoring rate and the highest penalty will be chosen depending on parameters. Now let us discuss where the maximum can be attained. Figure 2 shows the regions where the piecewise function (16) is defined. The level curve $\frac{\alpha G}{q_{i}(1-\alpha)}=g$ is also represented. Note that lower-laying level curves correspond to lower $g$-values. 


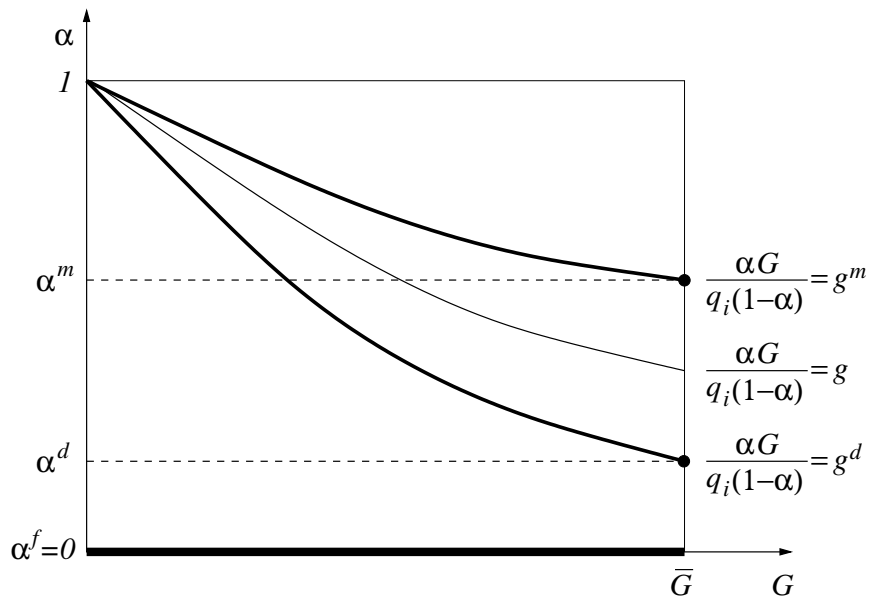

Figure 2: Regions

First, since $W(\cdot, \cdot)$ decreases with $\alpha$ on the region given by $0 \leq g<g^{d}$ (the lowest region in figure 2), the relative maxima have $\alpha=0$ on this region. Second, taking into account that $C S^{d}(g)+\pi_{i}^{d}(g)=\frac{q_{i}}{2}\left[\bar{\theta}^{2}-x_{i}^{d}(g)^{2}\right]$ decreases with $g$ (because $x_{i}^{d}(g)$ increases with $g$ ), on the intermediate region $\left(g^{d} \leq g \leq g^{m}\right)$, the relative maximum must be $(\alpha, G)=\left(\alpha^{d}, \bar{G}\right)$. Third, on the uppermost region $\left(g^{m} \leq g\right)$, the relative maximum is $(\alpha, G)=\left(\alpha^{m}, \bar{G}\right)$ because $W(\cdot, \cdot)$ decreases with $\alpha$ on this region. Therefore, the optimal policy must be reached at some $g=\frac{\alpha \bar{G}}{q_{i}(1-\alpha)} \in\left\{0, g^{d}, g^{m}\right\}$. This shows that the optimal monitoring rate must be some $\alpha \in\left\{\alpha^{f}, \alpha^{d}, \alpha^{m}\right\}$, where

$$
\alpha^{f}=0, \quad \alpha^{d}=\frac{q_{i} g^{d}}{q_{i} g^{d}+\bar{G}}, \quad \alpha^{m}=\frac{q_{i} g^{m}}{q_{i} g^{m}+\bar{G}} .
$$

Since $0<g^{d}<g^{m}$, we have $\alpha^{f}<\alpha^{d}<\alpha^{m}<1$.

From (16) and (17), we deduce that the optimal policy corresponds to the maximum of three values:

$$
W^{f}, \quad W^{d}-C^{d}, \quad W^{m}-C^{m},
$$

where $C^{d}=C\left(\alpha^{d}\right)<C^{m}=C\left(\alpha^{m}\right), W^{f}=C S^{f}+\pi_{i}^{f}+I_{p}^{f}, W^{d}=C S^{d}\left(g^{d}\right)+$ $\pi_{i}^{d}\left(g^{d}\right)$, and $W^{m}=C S^{m}+\pi_{i}^{m}$. Easy calculations from (12) and (15) imply the following relationship among the gross social welfare levels associated with the regimes $f, d$ and $m$ :

$$
W^{m}<W^{f}<W^{d} .
$$

Some known results holds in the present setting. From (17-19), we can deduce that there are some parameter values for which monitoring is the optimal outcome (the condition is $C^{d}<W^{d}-W^{f}$ ). Moreover, for the quadratic cost of monitoring $C(\alpha)=c \alpha^{2}$, we can also see that a decrease in $c$ increases that possibility. However, the present model implies new conclusions. The first one is stated in the following proposition (its proof is immediate): 
Proposition 2 Pure monopoly (i.e., blockaded piracy) never occurs in equilibrium.

The intuition is that the government prefers inducing deterred or accommodated piracy because of the greater gross social welfare and the lower cost of monitoring associated with these policies. To blockade piracy is too costly in terms of social welfare. ${ }^{14}$

From (17-19), we can deduce the following qualitative result about the optimal policy:

Proposition 3 The optimal anti-piracy policy depends on the cost of monitoring and the penalty:

(a) If the cost of monitoring is sufficiently low or the limit of the penalty is sufficiently high (in that case $C^{d}<W^{d}-W^{f}$ ), the government will induce deterred piracy by choosing a positive monitoring rate.

(b) If the cost of monitoring is sufficiently high and the limit of the penalty is sufficiently low (in that case $C^{d}>W^{d}-W^{f}$ ), the government will induce accommodated piracy by choosing no monitoring.

Although our model is very stylized, Proposition 3 reflects some known empirical evidence. Focusing on the installation of pirated software and using the broadest definition of piracy, Marron and Steel (2000) find that countries with weak economic institutions have significantly higher piracy rates than do countries with strong institutions. In our opinion, low costs of monitoring and high limits of the penalties could be associated with strong economic institutions. Therefore, parts (a) and (b) of Proposition 3 would be associated with strong and weak economic institutions respectively.

Let us conclude the present section with some comments on the lack of hypotheses about the government's budget.

Remark 1. Instead of a limit of the penalty, we could have assumed the standard balanced budget assumption in which there is no limit but the government is constrained to balance the budget in expected terms, i.e., $\alpha$ and $G$ must satisfy $\alpha G \equiv C(\alpha)$ [see, for instance, Banerjee (2003)]. The qualitative conclusions of our model also hold under the balanced budget assumption because, under this assumption, the optimal monitoring rates would be deduced from $g=\frac{C(\alpha)}{q_{i}(1-\alpha)} \in\left\{0, g^{d}, g^{m}\right\}$. In that case, the values of $\alpha^{f}, \alpha^{d}$ and $\alpha^{m}$ could be others but the qualitative properties of our conclusions would remain unchanged. In fact, under the balanced budget assumption, the monitoring rates in (17) can be obtained from the linear cost function $C(\alpha)=\alpha \bar{G}$.

Remark 2. Without a limit of the penalty and assuming a non negative government's net revenue (i.e., under the assumption $\alpha G \geq C(\alpha) \forall \alpha$ ), the optimal policy does not exist because the maximum of the welfare function in (16) does not exist. The reason is that, under those assumptions, we can easily obtain feasible sequences of monitoring rates and penalty levels $\left\{\left(\alpha_{k}, G_{k}\right)\right\}_{k}$, with $\alpha_{k} \rightarrow 0$ and $G_{k} \rightarrow+\infty$, such that $\lim _{k} \frac{\alpha_{k} G_{k}}{q_{i}\left(1-\alpha_{k}\right)} \in\left\{0, g^{d}, g^{m}\right\}$. Therefore, taking into account (19), the supremum of the social welfare function in (16) is equal to $W^{d}$, which cannot be attained at any feasible anti-piracy policy.

\footnotetext{
${ }^{14}$ This possibility may constitute an equilibrium in Banerjee (2003) because he considers a weaker pirate in strategical terms (see Section 2).
} 
These two remarks suggest that, in models where the government is responsible for monitoring and penalizing piracy, some hypotheses on feasible policies must be assumed regarding the for-profit piracy. The balanced budget assumption or a limit on the penalty can be viewed as two alternative and essentially equivalent hypotheses to guarantee the existence of an optimal policy. ${ }^{15}$

\section{The effects of qualities on the equilibrium}

This section is devoted to study by comparative statics the effects of an increase in the quality of the pirated product. In our model, this increase corresponds to a decrease in the ratio $r=q_{i} / q_{p}>1$ towards $r=1$, keeping constant $q_{i}$. Before deducing some results, let us consider the properties of the three relevant elements in our arguments: the differentiation degree, the incumbent's profit and the consumer surplus.

First, the effects of the differentiation degree depends on the initial quality differential. Whenever the qualities are similar, an increase in $q_{p}$ makes the product less differentiated. Therefore, the pirate's revenue decreases, the government has to put less effort to deter piracy and the social cost of deterring piracy (relative to accommodating it) falls. Whenever the qualities are very distinct, an increase in $q_{p}$ increases the pirate's revenue because the pirated product is differentiated enough and its quality increases. In consequence, the government has to put more effort and the social cost of deterring piracy increases.

Second, the incumbent's profit under deterred piracy equals the one under accommodated piracy (i.e., $\left.\pi_{i}^{d}\left(g^{d}\right)=\pi_{i}^{f}\right)$. The reason is that, if the government were going to induce deterred piracy, it would optimally choose the anti-piracy policy with no extra rent for the incumbent. Therefore, competition explains that the incumbent's profits decrease from $\pi_{i}^{m}$ to 0 when $q_{p}$ tends to $q_{i}$.

Third, the consumer surplus increases up to $q_{i} \bar{\theta}^{2} / 2$ (the competitive level) when $q_{p}$ tends to $q_{i}$, under both, accommodated and deterred piracy. In the first case, it is due to the improvement in the qualities available to consumers, but in the second case, the reason is that the incumbent's price (induced by the government) to deter piracy decreases.

A partial analysis of the effects of $q_{p}$ on piracy is provided by Banerjee (2003), who considers the pirate's demand as a measure of piracy. Assuming that the SPE involves accommodated piracy, he finds that piracy increases when the quality of pirated product increases. We can check this in our model, considering that the SPE is reached at $\alpha=\alpha^{f}=0$. In that case, easy calculations show that the pirate's demand is $D_{p}^{f}=\frac{r \bar{\theta}}{2(2 r-1)}$, which is a decreasing function of $r$. Nevertheless, this is a local conclusion. Taking into account the changes in the optimal government's decisions, the conclusion may be reversed. In the appendix we prove the following proposition, which shows that deterred piracy may be the SPE outcome if the quality of the pirated product is close to the original one. Therefore, a non local increase in the quality of the pirated product can imply a decrease in piracy.

\footnotetext{
${ }^{15}$ In a different setting, Kiema (2008) considers $b=\alpha G$ as a parameter to guarantee the existence of a solution.
} 
Proposition 4 When $C^{\prime}(0)<2 \bar{G}$ (or under the balanced budget assumption), the SPE implies deterred piracy if $q_{p}$ is sufficiently close to $q_{i}$.

To explain the proposition, consider the gross social benefit of deterring piracy compared with the social cost. On the one hand, since the incumbent's profits under deterred piracy and under accommodated piracy are identical, the gross social benefit of deterring piracy is the consumer benefit of deterring piracy minus the pirate's revenue. In analytical terms, we have $W^{d}-W^{f}=$ $\Delta\left(g^{d}\right)-I_{p}^{f}>0$, where $\Delta\left(g^{d}\right)=C S^{d}\left(g^{d}\right)-C S^{f}>0$ denotes the consumer benefit of deterring piracy (relative to accommodating it), which is positive for any $q_{p}<q_{i}$ because deterred piracy implies better quality at lower price. On the other hand, the social cost of deterring piracy is $C\left(\alpha^{d}\right)$.

In general, the comparison between $\Delta\left(g^{d}\right)-I_{p}^{f}$ and $C\left(\alpha^{d}\right)$ is ambiguous and depends on the combination of the parameters. However we can obtain some insights for some range of parameters.

Consider a low initial quality differential (i.e. the parametric region given by the neighborhood of $q_{p}=q_{i}$ ). When $q_{p}$ tends to $q_{i}$, the consumer benefit of deterring piracy, the pirate's revenue under accommodated piracy and the social cost of deterring piracy decrease until 0 . Therefore, the gross social benefit of deterring piracy will be above the social cost if $\Delta\left(g^{d}\right)-I_{p}^{f}$ decreases faster than $C\left(\alpha^{d}\right)$ when $q_{p}$ tends to $q_{i}$. Because $-I_{p}^{f}$ is increasing, when the initial quality differential is low, the gross social benefit of deterring piracy can be above the social cost only if the consumer benefit of deterring piracy is sufficiently decreasing. Therefore, the crucial element to explain Proposition 4 is that the increase in the consumer surplus implied by an increase in $q_{p}$ is stronger when piracy is accommodated than when it is deterred, in order to make $\Delta\left(g^{d}\right)$ decreasing enough. This is true for any $q_{p}<q_{i}$ because an increase in $q_{p}$ raises competition when the pirate is present in the market. This effect dominates the decrease in the pirate's revenue when qualities are similar, and may dominate even the corresponding decrease in the social cost (for instance, when the marginal cost of monitoring is sufficiently low or when the feasible policies are constrained by the balanced budget assumption).

Another point addressed in the literature is the effect of the quality of the pirated product on the optimal monitoring rate that deters piracy. ${ }^{16}$ In our model, we can wonder if $\alpha^{d}$ increases or not when $q_{p}$ increases. We know that this depends on $g^{d}$. Therefore, the above arguments concerning $g^{d}$ imply that the answer to our question depends on the initial quality differential and the size of the quality change. Proposition 4 provides a case in which the optimal monitoring rate $\alpha^{d}$ falls when $q_{p}$ increases. This happens whenever the initial quality differential is low enough and the marginal cost of monitoring is sufficiently low (or under the balanced budget assumption). The following proposition, whose proof is in the appendix, presents a case in which the conclusion is the contrary at least for local changes in $q_{p}$.

\footnotetext{
${ }^{16}$ See for instance Banerjee (2003).
} 
Proposition 5 Suppose that the cost of monitoring is linear. Then, when $q_{p}$ is sufficiently low relative to $q_{i}$, the SPE implies deterred piracy.

Proposition 5 provides a case in which the optimal monitoring rate $\alpha^{d}$ increases if $q_{p}$ increases locally. This occurs whenever the initial quality differential is high enough and the cost of monitoring is a linear function. Note that, even in this case, if we allow for non local increases of $q_{p}$, the optimal monitoring rate can decrease if $q_{p}$ increases.

Let us conclude this section with a corollary that stresses the role of the quality of the pirated product when the cost of monitoring is not a problem for the government.

Corollary 1 Suppose that the marginal cost of monitoring is constant and lower than $2 \bar{G}$. Then, the SPE implies deterred piracy if the quality differential is sufficiently low or sufficiently high. Otherwise, it implies accommodated entry.

\section{Simultaneous decisions}

In the previous sections we have assumed that the incumbent acts as a leader in prices and, therefore, the firm must be able to commit to a price. The purpose of this section is to show that this requirement is not important for the results. We approach the issue from an extended game in which, at Stage 1, the government announces the anti-piracy policy and, at the Stage 2, the incumbent decides between to make or not to make a credible commitment to a price. In the first case, the game continues as in the previous model (i.e., the incumbent acts as a leader in prices). In the second case, the incumbent and the pirate make simultaneous decisions. Note that the pirate decides on his price and also about entry.

Taking into account the framework exposed in Section 3, we can compute easily the incumbent's best response function:

$$
x_{i}^{B R}\left(x_{p}\right)= \begin{cases}\frac{x_{p}+\bar{\theta}(r-1)}{2 r} & \text { if } 0 \leq x_{p} \leq \frac{(r-1) \bar{\theta}}{2 r-1} \\ x_{p} & \text { if } \frac{(r-1) \bar{\theta}}{2 r-1} \leq x_{p} \leq \bar{\theta} / 2 \\ \bar{\theta} / 2 & \text { if } \bar{\theta} / 2 \leq x_{p} \leq \bar{\theta}, \text { or } x_{p}=+\infty\end{cases}
$$

where $x_{p}=+\infty$ means that the pirate does not entry. The proof is available upon request from the authors. Considering the pirate's best response function in (7), we can compute the unique pure strategy Nash equilibrium when the pirate enters the market. The superscript $s$ indicates "simultaneous choices":

$$
\begin{array}{ll}
x_{i}^{s}=\frac{2(r-1) \bar{\theta}}{4 r-1}, & \pi_{i}^{s}=\frac{4 q_{i} r(r-1) \bar{\theta}^{2}}{(4 r-1)^{2}} \\
x_{p}^{s}=\frac{(r-1) \bar{\theta}}{4 r-1}, & I_{p}^{s}=\frac{q_{i}(r-1) \bar{\theta}^{2}}{(4 r-1)^{2}} .
\end{array}
$$

Now, the level of anti-piracy effort $g=\frac{\alpha G}{q_{i}(1-\alpha)}$, for which the pirate is indifferent between enter or not, is obtained by solving $(1-\alpha) I_{p}^{s}=\alpha G$, and we find:

$$
g^{s}=\frac{(r-1) \bar{\theta}^{2}}{(4 r-1)^{2}} .
$$

Relative to the previous relevant values of $g$ in Proposition 1, we can check that $g^{d}<g^{s}<g^{m}$ holds. 
Before continuing the analysis, consider a more tractable extended game with a two-stage entry process in which the pirate decides first on entry and then, in the case of entry, the pirate chooses his price simultaneously with the incumbent (so that the pirate's entry decision before pricing is a credible commitment). ${ }^{17}$ In such a model, is it easy to show that the incumbent prefers not to make a credible commitment to a price and to move simultaneously with the pirate for any anti-piracy policy $g \in\left(g^{s}, g^{m}\right)$. The reason is that the incumbent's continuation optimal profit is $\pi_{i}^{d}(g)$ [in expression (15)] if he chooses to make a credible commitment to a price, but otherwise it is $\pi_{i}^{m}>\pi_{i}^{d}(g)$ because, in the corresponding subgame with simultaneous decisions, the pirate will not enter. For this kind of extended game, the conclusions obtained in previous sections should be revised taking into account the new relevant anti-piracy level (22).

Nevertheless, we will not analyze that kind of extended games, and we will assume a one-stage entry process in which entry and price are chosen simultaneously by the pirate. The reason is the consistency of the extended game: for the subgames associated to credible commitments to prices by the incumbent, we assume that the pirate's decision on entry before pricing is not a credible commitment. Therefore, in coherence with this, we also assume a one-stage entry process for the other subgames.

To calculate the Nash equilibria of each subgame with simultaneous decisions we assume that prices are deterministic (i.e., mixed strategies can only appear if the pirate randomizes his choice on entry). This is a common assumption in the literature when models have pure strategy equilibria in prices. In the extended game that we consider, for each anti-piracy policy, there is only one equilibrium with deterministic prices in the corresponding subgame with simultaneous decisions whenever the quality differential is high enough. In the appendix, we prove the following proposition that summarizes such equilibria.

Proposition 6 Assuming $r \geq 3 / 2$, the unique Nash equilibria with deterministic prices, when decisions are simultaneous, are the following:

(a) If $g \in\left[0, g^{s}\right]$, the incumbent will choose the price $x_{i}^{*}=x_{i}^{s}$ and the pirate will enter and choose the price $x_{p}^{*}=x_{p}^{s}$ with probability one.

(b) If $g \in\left(g^{s}, g^{m}\right)$, the incumbent will choose the price $x_{i}^{*}=x_{i}^{d}=2 \sqrt{(r-1) g}$, and the pirate will enter and choose the price $x_{p}^{*}=\sqrt{(r-1) g}$ with probability $\beta^{*}$ and will not enter with probability $1-\beta^{*}$, where

$$
\beta^{*}=\frac{r-1}{3}\left[\frac{\bar{\theta}}{\sqrt{(r-1) g}}-4\right] .
$$

(c) If $g^{m} \leq g$, the incumbent will choose the price $x_{i}^{*}=x_{i}^{m}$, and the pirate will not enter with probability one.

Remark 3. The condition $r \geq 3 / 2$ in Proposition 6 is tight. Whenever $1<r<3 / 2$, there is no equilibrium with deterministic prices. For instance, this can be checked for $\bar{\theta}=24$ and $r=5 / 4$. In this case, we have $g^{s}=9$ and $g^{m}=108$, but for $g=36$ there is no equilibrium with deterministic prices. This suggests that if the quality differential is low enough, the equilibria in a subgame with simultaneous decisions may imply random prices.

\footnotetext{
${ }^{17}$ This kind of approach to model simultaneous moves is common in the literature of commercial piracy.
} 
By comparing the incumbent's continuation optimal profit when he makes a credible commitment to a price (according to Proposition 1) with the corresponding one if he moves simultaneously with the pirate (according to Proposition 6), we obtain the incumbent's optimal choices in the subgame corresponding to each anti-piracy policy $g$.

For policies $g \in\left[0, g^{d}\right)$, the incumbent will obtain $\pi_{i}^{f}$ if he commits to a price, whereas his profit will be $\pi_{i}^{s}<\pi_{i}^{f}$ if he chooses simultaneously with the pirate. So, in this case, the incumbent will prefer to make a credible commitment to a price. When $g \in\left[g^{d}, g^{s}\right]$, since $x_{i}^{d}(g)<x_{i}^{f}$, we can prove easily that $\pi_{i}^{d}(g)>\pi_{i}^{s}$ and, therefore, the incumbent will also prefer to commit to a price. Whenever $g \in\left(g^{s}, g^{m}\right)$, the incumbent will obtain the profit $\pi_{i}^{d}(g)$ if he decides to make a credible commitment to a price, but otherwise he will get $\beta^{*} \hat{\pi}_{i}(g)+\left(1-\beta^{*}\right) \pi_{i}^{d}(g)$, where $\hat{\pi}_{i}(g)$ is the incumbent's profit when he chooses the price $x_{i}^{d}(g)$ and the pirate enters. Since $\pi_{i}^{d}(g)>\hat{\pi}_{i}(g)$, for these policies the incumbent also prefers to commit to a price. Finally, for policies $g \in\left[g^{m},+\infty\right)$, the incumbent is indifferent because entry is blockaded by the government independently of the incumbent's strategy. In consequence, we have the following result:

Proposition 7 For the extended game with $r \geq 3 / 2$, in any SPE with deterministic prices:

(a) The incumbent makes a credible commitment to a price and the incumbent and the pirate's optimal strategies are given in Proposition (1).

(b) Pure monopoly (i.e., blockaded piracy) never occurs in equilibrium, and the anti-piracy policy depends on the cost of monitoring and the penalty according to Proposition (3).

The intuition comes from two arguments. First, the optimal profits in a leader-follower setting are higher than in a framework with simultaneous choices of prices. Second, even if the incumbent deters piracy when he makes a credible commitment to a price, his profit is higher because the lack of commitment of the pirate's decision on entry.

\section{Conclusions}

In this paper we analyze the strategic decisions of the government, the incumbent and the pirate in a market where the good is piratable. In the model, after the government's anti-piracy policy is made public, the incumbent and the pirate compete in prices. Product is differentiated according to quality and consumers have different valuations of quality and buy at most one product. The government chooses the anti-piracy policy that maximizes the social welfare. 
In the first part of our analysis we assume that the incumbent moves first and chooses the price of the original product (becoming a leader in prices) and then, taking into account such price, the pirate decides whether to enter or not with a lower-quality version of the product. Our analysis implies new conclusions with respect to previous studies of commercial piracy. First, we show that the incumbent can deter the pirate from entry in equilibrium as a consequence of the government's policy. Second, we prove that pure monopoly (i.e., blockaded piracy) cannot occur in equilibrium for any anti-piracy policy. Third, we show that the standard property that an increase in the quality of pirated product increases piracy is a local conclusion: when the initial quality differential is low enough, an increase in the quality of pirated product may deter piracy if we consider the whole subgame perfect equilibrium. Forth, we show that the effects of an increase in the quality of the pirated product on the optimal monitoring rate which deters piracy depend on the initial quality differential. If it is low enough, an increase in the quality of the pirated product may decrease the optimal monitoring rate. Nevertheless, if it is high enough, a local increase in the quality of the pirated product may increase the optimal monitoring rate, but a non-local increase may decrease it.

In the second part of our analysis we consider an extended game in which the incumbent decides between to make a credible commitment to a price (becoming a leader in prices) or to choose simultaneously with the pirate. Considering a two-stage entry process, as in the standard way, we show that there are antipiracy policies for which the incumbent prefers to move simultaneously with the pirate. However, when we consider, in a more coherent fashion, a one-stage entry process (i.e., the pirate cannot commit to entry before pricing), we show that the incumbent prefers to make a credible commitment to a price whenever the quality differential is high enough. Therefore, under such circumstance, many of our previous conclusions are also valid for the extended game.

\section{Appendix}

Sketch of proof of Proposition 1. To maximize (9), we must obtain first the possible local maxima restricted to the intervals $I_{1}=\left[0, x_{i}^{d}(g)\right]$ and $I_{2}=\left[x_{i}^{d}(g), \bar{\theta}\right]$. The local maxima depends on parameters through the parabolas $\phi_{1}\left(x_{i}\right)=q_{i} x_{i}\left(\bar{\theta}-x_{i}\right)$ and $\phi_{2}\left(x_{i}\right)=q_{i} x_{i}\left(\bar{\theta}-\frac{2 r-1}{2(r-1)} x_{i}\right)$. The first parabola is the full monopoly profit function, which is maximized at $x_{i}=x_{i}^{m}$, and the second one is is the incumbent's profit function when the pirate enters the market and reacts optimally, which is maximized at $x_{i}=x_{i}^{f}$ with $\phi_{2}\left(x_{i}^{f}\right)=\pi_{i}^{f}$ (see (11), (10) and (15) for the specific values). Note that the parabola $\phi_{1}$ is always above the parabola $\phi_{2}$ on $[0, \bar{\theta}]$.

From the properties of (7) and (8), the maximization of $\pi_{i}^{c}(\cdot)$ in (9) leads us to compare

$$
\pi_{1 i}= \begin{cases}\phi_{1}\left(x_{i}^{d}(g)\right) & \text { if } 0 \leq g \leq g^{m} \\ \phi_{1}\left(x^{m}\right) & \text { if } g^{m} \leq g\end{cases}
$$

with 


$$
\pi_{2 i}= \begin{cases}\phi_{2}\left(x_{i}^{f}\right) & \text { if } 0 \leq g \leq \frac{(r-1) \bar{\theta}^{2}}{4(2 r-1)^{2}} \\ \phi_{2}\left(x_{i}^{d}(g)\right) & \text { if } \frac{(r-1) \bar{\theta}^{2}}{4(2 r-1)^{2}} \leq g \leq \frac{(r-1) \bar{\theta}^{2}}{(2 r-1)^{2}} \\ 0 & \text { if } \frac{(r-1) \bar{\theta}^{2}}{(2 r-1)^{2}} \leq g \leq \frac{\bar{\theta}^{2}}{4 r} \\ -\infty & \text { if } \frac{\bar{\theta}^{2}}{4 r}<g .\end{cases}
$$

Since $x_{i}^{d}\left(g^{m}\right)=\bar{\theta} / 2$, the situation of $g^{m}$, relative to the points $\frac{(r-1) \bar{\theta}^{2}}{4(2 r-1)^{2}}$, $\frac{(r-1) \bar{\theta}^{2}}{(2 r-1)^{2}}$ and $\frac{\bar{\theta}^{2}}{4 r}$, can be easily obtained. From (8), we deduce the expression (13) for $g^{m}$, and the inequalities $\frac{(r-1) \bar{\theta}^{2}}{4(2 r-1)^{2}} \leq g^{m} \leq \frac{\bar{\theta}^{2}}{4 r}$. Moreover, we have $\frac{(r-1) \bar{\theta}^{2}}{(2 r-1)^{2}} \lessgtr g^{m}$ if and only if $r \lessgtr 3 / 2$.

The rest of our proof compares $\pi_{1 i}$ with $\pi_{2 i}$, by separating the arguments into several cases, corresponding to different intervals for the values of $g$. A special price is $x_{i}^{0}=\bar{\theta}\left(1-(2 r-1)^{-1 / 2}\right) / 2<x_{i}^{f}$ such that $\phi_{1}\left(x_{i}^{0}\right)=\pi_{i}^{f}$ and the corresponding $g^{d}$ in (12) verifying $x_{i}^{d}\left(g^{d}\right)=x_{i}^{0}$. We find finally the cases specified in Proposition 1.

Proof of Proposition 4. Taking into account the profit and surplus levels in (15) and the gross welfare levels defined in (18), and the value of $g^{d}$ in (12), we can compute the gross social benefit of deterring piracy relative to accommodating piracy, which is a function of $r$ :

$$
\varphi(r)=W^{d}-W^{f}=\frac{q_{i} \bar{\theta}^{2}}{8}\left[\frac{3-5 r}{(2 r-1)^{2}}+\frac{2}{\sqrt{2 r-1}}\right] .
$$

The social cost of deterring piracy is, on the other hand, the function:

$$
\Psi(r)=C\left(\alpha^{d}\right),
$$

where $\alpha^{d}$ is defined in (17) and, under the balanced budget assumption, it is defined as $C\left(\alpha^{d}\right)=g^{d} q_{i}\left(1-\alpha^{d}\right)$, according to Remark 1 .

It is easy to show that, when $r \rightarrow 1+$, we have $g^{d} \rightarrow 0, \alpha^{d} \rightarrow 0, \varphi \rightarrow 0$, and $\Psi \rightarrow 0$. Therefore, to compare social benefits with social costs in the neighborhood of $r=1$, we compare $\varphi^{\prime}(1)$ with $\Psi^{\prime}(1)$. We have $\varphi^{\prime}(1)=q_{i} \bar{\theta}^{2} / 8$, and $\Psi^{\prime}(1)=\left[C^{\prime}\left(\alpha^{d}\right) \frac{\partial \alpha^{d}}{\partial g^{d}} \frac{\partial g^{d}}{\partial r}\right]_{r \rightarrow 1+}=C^{\prime}(0) \frac{q_{i}}{\bar{G}} \frac{\bar{\theta}^{2}}{16}$. Therefore, $C^{\prime}(0)<2 \bar{G}$ implies $\Psi^{\prime}(1)<\varphi^{\prime}(1)$, and the inequality $C\left(\alpha^{d}\right)<W^{d}-W^{f}$ holds when $r$ is close to 1 .

For the balanced budget assumption, we have that $\Psi^{\prime}(1)=\lim _{r \rightarrow 1+} \frac{\Psi(r)-\Psi(1)}{r-1}=$ $\lim _{r \rightarrow 1+} q_{i}\left(1-\alpha^{d}\right)\left[\frac{\partial g^{d}}{\partial r}\right]=q_{i} \bar{\theta}^{2} / 16$. In this case, $\Psi^{\prime}(1)<\varphi^{\prime}(1)$ holds without additional conditions. 
Proof of Proposition 5. Assume that the cost of monitoring is $C(\alpha)=c \alpha$. Consider the functions $\varphi(r)$ and $\Psi(r)$ defined in Proposition 4. From (12) and (17), we can obtain easily:

$$
\Psi(r)=\frac{c q_{i} \bar{\theta}^{2}(r-\sqrt{2 r-1})}{q_{i} \bar{\theta}^{2}(r-\sqrt{2 r-1})+8(r-1)(2 r-1) \bar{G}} .
$$

To compare $\varphi(r)$ with $\Psi(r)$, consider the transformation $r=\left(z^{2}+1\right) / 2$ which is one to one for $z>1$. We have $\varphi(r) \lessgtr \Psi(r)$ if and only if

$$
\left(1-5 z^{2}+4 z^{3}\right)\left[q_{i} \bar{\theta}^{2}(z-1)+8 \bar{G} z^{2}(1+z] \lessgtr 16 c(z-1) z^{4} .\right.
$$

If $z$ is high enough the left hand side in previous expression is greater than the right hand side, and this is equivalent to say that $\varphi(r)>\Psi(r)$ if $r$ is high enough. In consequence, we conclude $W^{d}-W^{f}>C\left(\alpha^{d}\right)$ whenever $q_{p}$ is sufficiently low relative to $q_{i}$.

Sketch of proof of Proposition 6. The curves of the best response functions in (7) and (20) intersects just once at $x_{i}=x_{i}^{s}$ and $x_{p}=x_{p}^{s}$ in (21). Now, with simultaneous decisions, there is an anti-piracy effort level $g^{s} \in\left(g^{d}, g^{m}\right)$ under which, the pirate is indifferent between enter or not. However, the price $x_{i}^{d}(g)$ in (8) is the minimal incumbent's price against that the pirate obtains non negative profits, and the price $x_{i}^{m}$ in (11) is the monopoly price. So, the equilibrium properties will depend on the relative positions of these prices. We divide the proof into several cases. Let $x_{i}^{*}$ and $x_{p}^{*}$ be the incumbent and the pirate's prices in a hypothetical Nash equilibrium.

When $g \in\left[0, g^{s}\right]$, we find that the incumbent's price $x_{i}^{*}=x_{i}^{s}$ and the pirate's strategy of entering and pricing $x_{p}^{*}=x_{p}^{s}$ constitute a Nash equilibrium, which is the unique one with deterministic prices. The uniqueness is shown by considering $\pi_{i}^{e}\left(x_{i}, x_{p}^{*} ; \beta\right)$, the expected incumbent's profit function when the pirate enters with some probability $\beta \in(0,1)$ and prices $x_{p}^{*}$. If there was an equilibrium $\left(x_{i}^{*}, x_{p}^{*}, \beta\right)$, we would have $x_{i}^{*}=x_{i}^{d}(g)$ and $x_{p}^{*}=x_{p}^{B R}\left(x_{i}^{*}\right)$ and $\beta \geq \beta^{*}$. The properties of $\beta^{*}$ in (23) would lead us to the contradiction $\beta \geq 1$.

When $g \in\left(g^{s}, g^{m}\right)$ and with deterministic prices, we find that the pirate must randomize on entry in equilibrium. We can deduce that the incumbent will try to deter entry by pricing $x^{d}(g)$ in (8), but the pirate will enter with probability $\beta^{*}$ in $(23)$ and price $x_{p}^{*}=x_{i}^{d}(g) / 2$. On the one hand, the expected incumbent's profit function $\pi_{i}^{e}\left(x_{i}, x_{p}^{*} ; \beta\right)$ must be maximized at $x_{i}=x_{i}^{d}(g)$, and this implies $\beta=\beta^{*}$. On the other hand, we can show that $x_{i}=x_{i}^{d}(g)$ is the unique maximum of $\pi_{i}^{e}\left(\cdot, x_{p}^{*} ; \beta^{*}\right)$.

For the rest of cases, we find that in the unique equilibrium with deterministic prices the pirate does not enter and the incumbent prices $x_{i}^{*}=x_{i}^{m}$. 


\section{References}

S. H. Bae and J. P. Choi. A model of piracy. Information Economics and Policy, 18(3):303-320, 2006.

J. Bain. Barriers to New Competition. Cambridge, Mass.: Harvard University Press., 1956.

D. S. Banerjee. Software piracy: a strategic analysis and policy instruments. International Journal of Industrial Organization, 21:97-127, 2003.

D. S. Banerjee. Lobbying and commercial software piracy. European Journal of Political Economy, 22:139-155, 2006.

P. Belleflamme. Versioning in the information economy: Theory and applications. CESifo Economic Studies, 51(2-3):321-328, 2005.

M. C. Chang, C. F. Lin, and D. Wu. Piracy and limited liability. Journal of Economics, 95(1):25-53, 2008.

C. Crampes and A. Hollander. Duopoly and quality standards. European Economic Review, 39:71-82, 1995.

I. Kiema. Commercial piracy and intellectual property policy. Journal of Economic Behavior \&G Organization, 68(1):304-318, 2008.

D. B. Marron and D. G. Steel. Which countries protect intellectual property? the case of software piracy. Economic Inquiry, 38(2):159-174, April 2000.

F. Martínez-Sánchez. Avoiding commercial piracy. Information Economics and Policy, 22(4):398-408, 2010.

M. Motta. Endogenous quality choice: Price vs. quantity competition. The Journal of Industrial Economics, 41(2):113-131, June 1993.

T. Papadopoulos. Determinants of international sound recording piracy. Economics Bulletin, 6(10):1-9, 2003.

M. Peitz and P. Waelbroeck. Piracy of digital products: A critical review of the theoretical literature. Information Economics and Policy, 18:449-476, 2006.

S. Poddar. Network externality and commercial software piracy. Working Paper 0516, National University of Singapore, Department of Economics, 2005a.

S. Poddar. Why software piracy rates differ. a theoretical analysis. Working Paper 0515, National University of Singapore, Department of Economics, 2005b.

U. Ronnen. Minimum quality standards. fixed costs, and competition. RAND Journal of Economics, 22(4):490-504, Winter 1991.

J. Tirole. The Theory of Industrial Organization. MIT Press, Cambridge, Mass, 1988.

H. R. Varian. Markets for information goods. In K. O. T. Inoue, editor, Monetary Policy in a World of Knowledge-Based Growth. Quality Change and Uncertain Measurement. Macmillan Press, 2001a.

H. R. Varian. Versioning information goods. In B. Kahin and H. R. Varian, editors, Internet Publishing and Beyond: The Economics of Digital Information and Intellectual Property. MIT Press, 2001b.

X. Wauthy. Quality choice in models of vertical differentiation. The Journal of Industrial Economics, 44(3):345-353, September 1996. 


\section{PUBLISHED ISSUES *}

WP-AD 2010-01 "Scaling methods for categorical self-assessed health measures"

P. Cubí-Mollá. January 2010.

WP-AD 2010-02 "Strong ties in a small world"

M.J. van der Leij, S. Goyal. January 2010.

WP-AD 2010-03 “Timing of protectionism”

A. Gómez-Galvarriato, C.L. Guerrero-Luchtenberg. January 2010.

WP-AD 2010-04 "Some game-theoretic grounds for meeting people half-way"

P.Gadea-Blanco, J.M. Jiménez-Gómez, M.C. Marco-Gil. February 2010.

WP-AD 2010-05 "Sequential city growth: empirical evidence"

A. Cuberes. February 2010.

WP-AD 2010-06 "Preferences, comparative advantage, and compensating wage differentials for job routinization"

C. Quintana-Domeque. February 2010.

WP-AD 2010-07 "The diffusion of Internet: a cross-country analysis"

L. Andrés, D. Cuberes, M.A. Diouf, T. Serebrisky. February 2010.

WP-AD 2010-08 "How endogenous is money? Evidence from a new microeconomic estimate"

D. Cuberes, W.R. Dougan. February 2010.

WP-AD 2010-09 "Trade liberalization in vertically related markets"

R. Moner-Colonques, J.J. Sempere-Monerris, A. Urbano. February 2010.

WP-AD 2010-10 "Tax evasion as a global game (TEGG) in the laboratory"

M. Sánchez-Villalba. February 2010.

WP-AD 2010-11 "The effects of the tax system on education decisions and welfare"

L.A. Viianto. March 2010.

WP-AD 2010-12 “The pecuniary and non-pecuniary costs of job displacement. The risky job of getting back to work"

R. Leombruni, T. Razzolini, F. Serti. March 2010.

WP-AD 2010-13 "Self-interest and justice principles"

I. Rodríguez-Lara, L. Moreno-Garrido. March 2010.

WP-AD 2010-14 "On spatial equilibria in a social interaction model”

P. Mossay, P.M. Picard. March 2010.

WP-AD 2010-15 "Noncooperative justifications for old bankruptcy rules"

J.M. Jiménez-Gómez. March 2010.

WP-AD 2010-16 "Anthropometry and socioeconomics in the couple: evidence from the PSID"

S. Oreffice, C. Quintana-Domeque. April 2010.

WP-AD 2010-17 "Differentiated social interactions in the US schooling race gap"

L.J. Hall. April 2010.

\footnotetext{
* Please contact Ivie's Publications Department to obtain a list of publications previous to 2010.
} 
WP-AD 2010-18 “Things that make us different: analysis of variance in the use of time”

J. González Chapela. April 2010.

WP-AD 2010-19 "The role of program quality and publicly-owned platforms in the free to air broadcasting industry”

M. González-Maestre, F. Martínez-Sánchez. June 2010.

WP-AD 2010-20 "Direct pricing of retail payment methods: Norway vs. US"

F. Callado, J. Hromcová, N. Utrero. June 2010.

WP-AD 2010-21 “Sexual orientation and household savings. Do homosexual couples save more? B. Negrusa, S. Oreffice. June 2010.

WP-AD 2010-22 “The interaction of minimum wage and severance payments in a frictional labor market: theory and estimation"

C. Silva. June 2010.

WP-AD 2010-23 "Fatter attraction: anthropometric and socioeconomic matching on the marriage market”

P.A. Chiappori, S. Oreffice, C. Quintana-Domeque. June 2010.

WP-AD 2010-24 “Consumption, liquidity and the cross-sectional variation of expected returns"

E. Márquez, B. Nieto, G. Rubio. July 2010.

WP-AD 2010-25 “Limited memory can be beneficial for the evolution of cooperation"

G. Horváth, J. Kovárík, F. Mengel. July 2010.

WP-AD 2010-26 “Competition, product and process innovation: an empirical analysis”

C.D. Santos. July 2010.

WP-AD 2010-27 “A new prospect of additivity in bankruptcy problems”

J. Alcalde, M.C. Marco-Gil, J.A. Silva. July 2010.

WP-AD 2010-28 "Diseases, infection dynamics and development”

S. Chakraborty, C. Papageorgiou, F. Pérez Sebastián. September 2010.

WP-AD 2010-29 "Why people reach intermediate agreements? Axiomatic and strategic justification” J.M. Jiménez-Gómez. September 2010.

WP-AD 2010-30 “Mobbing and workers’ health: an empirical analysis for Spain” M.A. Carnero, B. Martínez, R. Sánchez-Mangas. September 2010.

WP-AD 2010-31 "Downstream mergers in a vertically differentiated unionized oligopoly” A. Mesa-Sánchez. October 2010.

WP-AD 2010-32 “Endogenous quality choice under upstream market power” B. Mesa-Sánchez. November 2010.

WP-AD 2010-33 “Itemised deductions: a device to reduce tax evasion”

A. Piolatto. November 2010.

WP-AD 2010-34 “A unified theory of structural change”

M.D. Guilló, C. Papageorgiou, F. Pérez-Sebastián. December 2010.

WP-AD 2011-01 "Solving the multi-country real business cycle model using ergodic set methods" S. Maliar, L. Maliar, K. Judd. January 2011.

WP-AD 2011-02 “Anti-piracy policy and quality differential in markets for information goods” J.M. López-Cuñat, F. Martínez-Sánchez. January 2011. 


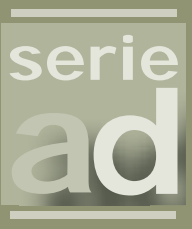

\section{I vie}

Guardia Civil, 22 - Esc. 2, 1 o

46020 Valencia - Spain

Phone: +34963190050

Fax: +34 963190055

Department of Economics

University of Alicante

Campus San Vicente del Raspeig

03071 Alicante - Spain

Phone: +34965 903563

Fax: +34965903898

Website: www.ivie.es

E-mail: publicaciones@ivie.es 